\title{
BREVES ANOTAÇÕES SOBRE AS ESPÉCIES NORMATIVAS DO CÓDIGO CIVIL
}

\author{
BRIEF NOTES ABOUT THE NORMATIVE SPECIES OF THE CIVIL CODE
}

Thiago Sales de Oliveira

\author{
Mestrando em Direito Processual pela Universidade Federal do Espírito Santo \\ (UFES). Cursa a especialização em Direito Processual (modalidade à distância) pela \\ Pontifícia Universidade Católica de Minas Gerais (PUC - Minas). Email: \\ t.salesdeoliveira@gmail.com
}

Recebido em: 28/05/2014 Aprovado em: 19/08/2014

Doi: $10.5585 /$ rdb.v13i6.139

\begin{abstract}
RESUMO: Considerado historicamente como o ponto de partida para os demais ramos jurídicos, o direito civil desfruta da afeição da doutrina e do apreço do legislador. Tal apreço é perceptível no esmero com o qual se empreendeu a confecção da nova codificação civil brasileira, caracterizada por modificar o cânone da aplicação normativa por simples subsunção, hegemônico no século passado, para uma nova postura, dessa vez, pautada na fortificação da atividade criadora da jurisprudência. Tal fenômeno, chamado por muitos de paradigma judicativo-decisório, estabelece o início de um novo período no panorama jurídico brasileiro: uma época de acentuada consulta aos valores, aos princípios e aos anseios da sociedade. A causa essencial de tais mudanças pode ser encontrada nas características das normas provenientes da nova codificação. $\mathrm{O}$ estudo das normas cíveis, a partir da lógica jurídica, é capaz de revelar que o tipo estrutura hipotético-condicional formulada pelo intérprete no momento da aplicação do direito possui prévia configuração estrutural, e que dominando os elementos de tal configuração, o intérprete-aplicador - na função de juiz será capaz de produzir as modificações necessárias na realidade fática, sempre visando à paz social, objetivo de todo processo. Formalizando as cláusulas gerais, os conceitos jurídicos indeterminados e os princípios, o intérprete do direito possuirá uma poderosa ferramenta intelectual no exercício de sua atividade, a qual será feita alusão durante este trabalho, utilizando-se, por vezes, de exemplos colhidos da jurisprudência pátria.
\end{abstract}

Palavras-chave: Norma; Lógica; Estrutura; Vagueza.

\begin{abstract}
Historically considered as the starting point for the other legal branches, the civil law enjoys the affection of the doctrine and the appreciation of the legislator. This appreciation, noticeable in the care with which they undertook the preparation of the new Brazilian civil encoding, where the use of so-called vague concepts prevailed over production of specific rules, changing the regulatory application by simple canon subsumption, hegemonic in the last century, to a new attitude this time, based on creative activity fortification of jurisprudence. This phenomenon establishes the beginning of a new period in the Brazilian legal panorama: an era of sharp consulting the values, principles and to the concerns of society. The essential cause of such changes can be found in the characteristics of
\end{abstract}


standards arising from the new encoding. The study of civil standards from legal logic is able to reveal that the hypothetical conditional-type structure formulated by the interpreter at the time of application of the law has structural configuration and preview it, mastering the elements of such a configuration, the interpreter-applicator - in the function of judge - will be able to produce the necessary changes in the social reality, seeking, always, the much desired peace, objective of the process. Formalizing the general clauses, the indeterminate legal concepts and the so acclaimed principles, will own the interpreter of a powerful tool in the exercise of their intellectual activity, which will be mentioned during this work, using sometimes picked examples of jurisprudence.

Keywords: Norm; Logic; Structure; Vagueness.

Sumário: Introdução; 1. Linguagem, Direito e Normas Jurídicas; 2. Lógica; 3. Lógica Jurídica; 4. As Espécies; 4.1 Aspectos Iniciais; 4.2 As Técnicas Legislativas e a Indeterminação dos Enunciados; 4.3 Princípios; 4.4 Cláusulas Gerais e Conceitos Jurídicos Indeterminados; 4.5 Regras de Conduta; 5. O Precedente Judicial como uma Possível Solução; Considerações Finais; Referências.

\section{INTRODUÇÃO}

A chegada do século XXI expandiu os horizontes investigativos do jurista brasileiro. Este, agora, se vê desafiado intelectualmente ao se deparar com a diversidade de espécies normativas presentes na codificação de 2002. Construído mediante a técnica legislativa das normas vagas ${ }^{l}$, o atual Código Civil permite a constante revitalização do sistema jurídico, comunicando inúmeros diplomas (Constituição e microssistemas) e recepcionando os anseios e preceitos que emanam da sociedade. Ao mesmo tempo, o novo código demanda daqueles que o utilizam o conhecimento de algumas questões prévias de suma importância.

A aplicação imediata da norma por subsunção, em que pese sua ainda inegável relevância, não ocupa mais a posição de principal processo intelectivo a ser desenvolvido na atividade jurídica cotidiana. Em nosso tempo, é exigida a capacidade de diferenciar conceitos, de relacioná-los e, principalmente, de complementá-los, em um esforço dialético entre aquilo que está contido na linguagem do sistema de direito positivo e aquilo que captamos da realidade social. Tal exigência não é feita somente aos juízes, protagonistas, é verdade, da posição de maior responsabilidade na atividade jurisdicional contemporânea.

Recai também sobre os advogados, promotores incansáveis dos valores da ordem jurídica, e aos estudantes, depositários de um conhecimento que se renova constantemente, mas que não deve perder de forma alguma sua finalidade. $\mathrm{E}$ a finalidade de todo conhecimento jurídico revelado pela ciência do direito é servir de apoio para a aplicação das normas que os cientistas se colocam a descrever, envolvendo o jurista em um esforço constante para a manutenção e explicação do sistema que lhe serve de objeto, com todos os valores que lhe são intrínsecos e sem os quais a convivência se tornaria inviabilizada.

Em nossa época, essa postura investigativa deve ser reforçada, dado que o próprio objeto apresenta dificuldades de operacionalização que requerem uma meticulosa análise por parte daqueles que estudam as normas e uma intensa reflexão pelos incumbidos de aplicá-las. É irrefutável que o magistrado foi investido de novos poderes com a codificação de 2002. Sua mobilidade interna ao sistema de direito positivo aumentou, e, com ela, a discricionariedade

${ }^{1}$ Ou como prefere uma parcela da doutrina, dos conceitos vagos.

Revista de Direito Brasileira | São Paulo, SP | v. 13 | n. 6 | p. 111 - 130 | jan./abr. 2016 
acerca da melhor solução para a lide levada a juízo, na qual deve prevalecer uma necessária correspondência entre os seus atos e o tipo de Estado sob o qual nos encontramos.

A atual seara cível permite que o intérprete-aplicador não apenas formule uma norma a partir de um enunciado previamente estabelecido, mas que também crie o consequente e mesmo parte do antecedente da norma jurídica pré-estabelecida, de acordo com o caso concreto. Não é apenas a subsunção de uma regra específica a um fato: é a criação de novas respostas legitimadas pelo ordenamento. Preocupa-nos encontrar limitações para tal discricionariedade, bem como parâmetros adequados para as decisões judiciais prolatadas em tal contexto. Nossa investigação se desenvolve com esse objetivo.

Aceitamos, de pronto, o sistema do direito positivo como um objeto de estudo constituído em linguagem e, portanto, passível de análise semiótica em diversos planos. É sobre ele que concentraremos nossas intenções, descrevendo as propriedades de suas unidades para enfrentar o tema proposto. $\mathrm{O}$ instrumento para esta empreitada será a lógica jurídica, que nos permitirá estudar com profundidade a linguagem acima referida, estabelecendo, pela formalização, os meios para diferenciarmos as espécies normativas e, consequentemente, as peculiaridades apresentadas por cada uma delas no momento de sua aplicação.

\section{LINGUAGEM, DIREITO E NORMAS JURÍDICAS}

Entender o direito como um objeto constituído em linguagem não significa estudá-lo somente tendo em vista o conteúdo prescrito pelos dispositivos do texto normativo. Reduzi-lo à lei consubstanciada em um conjunto de enunciados prescritivos impressos sobre determinado suporte físico seria ignorar a amplitude do fenômeno linguístico no qual o homem está inserido, cerceando a existência de um contexto cultural que o permeia ${ }^{2}$. Ignorar o panorama linguístico é negar os instrumentos necessários ao entendimento do direito positivo, e, de maneira mais precisa, o domínio sobre suas unidades básicas: as normas jurídicas.

O direito ${ }^{3}$ é um conjunto de normas que surgem como fruto da atividade de interpretação realizada pelo homem para construir o sentido normativo do texto legislativo. Por sua vez, estas normas podem ser tomadas como "[...] unidades dotadas de sentido deôntico, obtidas mediante o grupamento de significações organizadas em um arquétipo formal de implicação [...]", articula suas significações e compõe a norma jurídica. Esta será sempre portadora de uma estrutura hipotético-condicional na qual se encontrará regulamentada a conduta humana.

A norma jurídica define a ordem social, afastando o caos e impondo a convivência pacífica. Porém, não se percebe sensorialmente uma norma jurídica, não se trabalha tal objeto como o escritor escreve o papel ou o marceneiro esculpe a madeira. É necessário um esforço intelectivo ainda maior para apreendê-la, já em sua formação, na própria mente do intérprete. Assim, o jurista tem a responsabilidade não só com o produto final, o resultado de sua atividade, qual seja, a conduta manifesta no mundo fático, seja por livre vontade das partes ou através da sanção resultante da aplicação normativa.

\footnotetext{
${ }^{2}$ MOUSSALLEM, Tárek Moysés. Fontes do direito tributário. São Paulo: Noeses, 2006. p. 67.

${ }^{3}$ Ou de maneira mais precisa, o sistema do direito positivo.

${ }^{4}$ CARVALHO, Paulo de Barros. Direito tributário: fundamentos jurídicos da incidência. São Paulo: Saraiva 1998. p.19-20.
} 
Do mesmo modo, cabe a ele a diligência na formulação da norma jurídica, obedecendo a uma lógica única, qual seja, a lógica jurídica. Apesar de ao decorrer deste trabalho aparecerem diversas referências ao texto de dispositivos contidos no Código Civil brasileiro, devemos sempre ter em mente que os signos ali impressos são apenas elementos de um enunciado prescritivo. $\mathrm{O}$ signo $^{5}$ é aqui entendido como a unidade básica através da qual o intérprete do direito é capaz de entender o enunciado, ${ }^{6}$ para então relacionar as significações isoladas ${ }^{7}$ obtidas, resultando na formulação da norma jurídica. ${ }^{8}$

A palavra é um signo ${ }^{9}$ mais ou menos arbitrário, convencionado pelos usuários de determinada linguagem. É um dos meios de expressão dos indivíduos que habitam determinada cultura. A norma jurídica é o produto final de um processo que começa com a leitura das palavras, mas não se confunde com elas: está em um plano superior. Àqueles que se arriscam no estudo do direito positivo, cabe uma advertência: a norma jurídica é objeto de estudo primordial do jurista. Ainda que no estudo do direito possam ser abordados temas relativos à sociologia ou à filosofia, a norma jurídica deve ser o foco de nossa atenção.

Cada ciência se exprime mediante determinada linguagem que deve ser construída com a exatidão necessária para o controle adequado de seu objeto. Nossa investigação também será expressa linguisticamente, compondo um minus da ciência do direito atual: o sistema composto por enunciados produzidos pelos estudiosos do direito, em contraposição ao sistema de direito positivo, em que somente um ato de vontade proveniente de uma autoridade legítima é capaz de adentrar à sua composição, com disposição de prescrever ao invés de descrever.

A ciência do direito não poderia ser assim denominada se sua atividade não fosse dominada pela vontade racionalmente dirigida de explicar seu objeto, assim como as peculiaridades deste. Não é negado que o direito, enquanto um sistema de normas jurídicas dotadas de caráter coercitivo possa ser passível de determinada influência da moral e dos costumes de um povo, em virtude de seu caráter cultural e de ser fruto de um ato de produção

\footnotetext{
${ }^{5}$ Tárek Moysés Moussallem explica que: "Os signos (mais precisamente os símbolos) são convenções realizadas pelos sujeitos para representar o mundo físico. São concepç̃oes pactuadas das quais o homem (como ser cultural que é) compartilha, ao nascer em um mundo cultural". MOUSSALLEM, Tárek Moysés. Fontes do direito tributário. São Paulo: Noeses, 2006. p.2.
}

${ }^{6}$ Tomaremos os signos (ou, mais precisamente, os símbolos) como os elementos básicos da linguagem. Um olhar mais atento, contudo, perceberá que o morfema é a unidade mínima da linguagem, possuindo, ainda, alguma significação. São os signos que permitem a elaboração de mensagens entre os usuários da linguagem que desejam transmitir informações, possibilitando a comunicação entre os sujeitos.

${ }^{7}$ Entidades isoladas (ideias, conceitos e percepções) derivadas do entendimento do signo presente no texto, que passarão por um processo de dialética recíproca atingindo, por fim, o sentido deôntico do mesmo.

\footnotetext{
8“A palavra "norma" procede do latim: norma, e na língua alemã tomou o caráter de uma palavra de origem estrangeira - se bem que não em caráter exclusivo, todavia, primacial. Com o termo se designa um mandamento, uma prescrição, uma ordem. Mandamento não é, todavia, a única função da norma. Também conferir poderes, permitir, derrogar são funções de normas”. KELSEN, Hans. Teoria geral das normas. Tradução de José Florentino Duarte. Porto Alegre: Fabris, 1986. p.1.

${ }^{9}$ Os signos podem ser classificados em índices, ícones e símbolos. Índice é o signo que mantém uma conexão física com o objeto que indica. $\mathrm{O}$ ícone, por sua vez, procura reproduzir de algum modo o objeto a que se refere, oferecendo traços de semelhança ou refletindo atributos que estão no objeto representado. O símbolo se constitui em um signo arbitrariamente construído, não guardando, em princípio, qualquer ligação com o objeto a que ele alude.
} 
legislativa de uma comunidade humana. Na esteira de Kelsen, o direito é campo de disputa política e da afirmação de valores. ${ }^{10}$

Conforme este mesmo autor, o que deve ser isento de preceitos morais é o direito ${ }^{11}$ enquanto ciência: sistema que tem por finalidade a descrição das normas jurídicas válidas de determinado país, cuja pretensão científica deve ser independente de qualquer juízo sobre a legitimação ou justificação do objeto em investigação, campos que, invariavelmente, nos levariam à seara da ética ou da sociologia. Decidido que a norma jurídica é o principal foco das atenções dos estudiosos do direito, resta-nos a seguinte questão: sob qual ângulo seria mais adequado estudá-las?

Como um objeto de estudo constituído em linguagem, interessa-nos a análise do direito positivo a partir da lógica jurídica, instrumento capaz de delinear a norma jurídica em partes bem identificadas, mediante as quais poderemos explicar, com maior clareza, os tipos normativos a partir de sua configuração, com implicações na atividade judicante a ser desenvolvida pelo Estado-juiz. Para tanto, é necessária uma simplória introdução à lógica, que apesar de seu nascimento e desenvolvimento a partir da atividade filosófica, possui ampla utilização nas mais variadas ciências.

\section{LÓGICA}

O estudo da lógica ${ }^{1213}$ é uma empreitada única e magnífica. ${ }^{14}$ Desde que se deu conta de sua habilidade intelectiva para organizar conteúdos e formular raciocínios, o homo sapiens procura se distinguir pela capacidade de organizar seus pensamentos, de os transmitir, de torná-los mais aceitáveis e aptos ao entendimento. Seja em uma conversa cotidiana com um

\footnotetext{
${ }^{10}$ SGARBI, Adrian. Clássicos da teoria do direito. Rio de Janeiro: Lumen Juris, 2006. p. 33.

${ }^{11}$ Em essência, é uma discussão que tem origem na ambiguidade contida na palavra direito.

${ }^{12} \mathrm{O}$ termo lógica tem sua origem no vocábulo logos, que na língua grega significava inicialmente a palavra escrita ou falada: o verbo. Contudo, a partir de Heráclito, tal termo passou a ter um significado mais amplo. Logos passa a ser um conceito filosófico traduzido como razão: tanto como a capacidade de racionalização individual ou como um princípio cósmico da ordem e da beleza.
}

\footnotetext{
13،[...] A lógica é um instrumento do pensamento para pensarmos corretamente. Não se referindo a nenhum ser, a nenhuma coisa, a nenhum objeto, a lógica não se refere a nenhum conteúdo, mas à forma ou às formas do pensamento ou às estruturas do raciocínio em vista de uma prova ou de uma demonstração. [...] A lógica é o que devemos estudar e aprender antes de iniciar uma investigação filosófica ou científica, pois somente ela pode indicar qual é o tipo de proposição, de raciocínio, de demonstração, de prova e de definição que uma determinada ciência deve usar”. CHAUÍ, Marilena. Introdução à história da filosofia: dos pré-socráticos a Aristóteles. V.1. 2. ed. São Paulo: Companhia das Letras, 2002. p. 346.

14،'Discutem, tanto os lógicos como os filósofos, se a lógica é uma ciência teórica ou uma ciência normativa ou apenas uma arte ou técnica. Naturalmente, não vamos reproduzir aqui essas longas discussões, mas poderíamos dizer que todos têm o seu fundo de razão, porque ela pode ser encarada, empregada e estudada por qualquer um desses aspectos. É uma ciência teórica, quando especula sobre os elementos que formam o seu arcabouço; é normativa, quando oferece regras pelas quais podemos aquilatar se um pensamento está certo ou errado. Assim ela atende a todos esses aspectos, o que não impede que os desejosos de se embrenhar apenas na lógica teórica o façam, enquanto outros estudam apenas a sua aplicação normativa [...]”. SANTOS, Mário Ferreira dos. Lógica e dialética: lógica, dialética, decadialética. 4. ed. São Paulo: Logos, 1959. p. 19.
} 
amigo ou em uma conferência internacional, somos seres intensamente sociáveis e, portanto, capazes de criar expectativas junto àqueles que compartilham de nossos momentos comunicativos.

Contudo, o "fazer-se entender" não é uma tarefa fácil. Exige o conhecimento das técnicas, a prática reiterada e o estado de espírito apropriado, ou seja, uma verdadeira junção de teoria e prática. Ainda que pensar seja uma atividade inerentemente humana, e, como sabemos, na maioria das vezes descontrolada, nossos mecanismos de comunicação ${ }^{15}$ podem se unir a essa costumeira desordem para criar uma situação de caos comunicativo, privando de sentido nossas palavras, invalidando nossas proposições, jogando-nos ao solipsismo e à rejeição, ainda que, no fundo, estejamos com a "razão".

Os fundadores do pensamento ocidental - os filósofos gregos - já eram atentos ao perigo dessas circunstâncias e, dentre eles, surgiria um homem com aptidão e inteligência suficientes para organizar um estatuto suficientemente coerente que nos ensinasse a organizar nossos pensamentos e a transmiti-los com sucesso: Aristóteles. ${ }^{16}$ Discípulo de Platão e professor do grande conquistador Alexandre, Aristóteles deixaria sua contribuição em diversos campos do conhecimento. Mas é na lógica que sua genialidade desponta como única e insubstituível.

Aristóteles enxerga a lógica (e o raciocínio) como um instrumento, ${ }^{17}$ como uma introdução para as ciências e para o conhecimento, alicerçada primordialmente no silogismo ${ }^{18}$ : o raciocínio formalmente estruturado que supõe certas premissas colocadas previamente para que haja uma conclusão necessária. O silogismo é dedutivo, parte do universal para o particular; a indução, ao contrário, parte do particular para o universal. Dessa forma, se as premissas forem verdadeiras, logicamente, a conclusão também será. Tal filósofo prima sempre pela coerência e pela inteligibilidade do conteúdo enunciado.

De uma maneira geral, podemos considerar que, tal como é usada na filosofia e na matemática, a lógica observa sempre os mesmos princípios fundamentais: a lei do terceiro excluído, a lei da não-contradição e a lei da identidade. A esse tipo de lógica, que podemos chamar de "lógica clássica", tem sido atribuída a característica de substrato fundamental para

\footnotetext{
${ }^{15}$ A linguagem, tomada em um sentido amplo de transmissão de significados por meio de signos.

${ }^{16}$ Órganon é o nome tradicionalmente dado ao conjunto das obras de lógica deste filósofo. Significa "instrumento", pois os aristotélicos consideravam que o raciocínio (principal assunto da lógica) era um instrumento para a filosofia, ou seja, algo que precisava ser dominado antes de se poder produzir conhecimento ou ter uma prática de vida filosófica.
}

17،Há, pois, no Órganon de Aristóteles, uma série de regras que se destinam a proporcionar, ao ser dotado de raciocínio, os instrumentos que lhe possibilitem compreender e colocar em prática o raciocínio. Aliás, este é o grande legado de Aristóteles, presente em sua lógica, pois antes do estagirita a preocupação dos filósofos centrava-se, em especial, em criar métodos de sustentação de argumentos nos debates públicos, surgindo neste enfoque a dialética aristotélica que, diferentemente de Platão, ganha uma forte vertente política”. SILVA, Ivan de Oliveira. Curso de lógica geral e jurídica. São Paulo: Atlas, 2009. p. 11.

\footnotetext{
${ }^{18}$ Nesse exato sentido se expressa o referido filósofo em uma passagem dos analíticos anteriores, obra que compõe o Órganon: "Nossa próxima tarefa consiste em descrever como nós mesmos descobriremos um bom suprimento de silogismos [que nos capacite] a enfrentar qualquer problema dado e por qual método apreenderemos os princípios apropriados a cada problema, pois é de presumir que não devemos nos restringir a especular a cerca da formação dos silogismos, mas também munirmos da capacidade de construí-los". ARISTÓTELES. Órganon: categorias, da interpretação, analíticos anteriores, analíticos posteriores, tópicos, refutações sofísticas. Tradução, textos adicionais e notas de Edson bini. 2. ed. São Paulo: Edipro, 2010. p. 169.
} 
as reflexões de outros pensadores, que, vivendo em diferentes épocas, procuraram se utilizar dela em suas indagações e estudos. Um desses notórios pensadores foi Pedro Abelardo.

Teólogo e filósofo do século XII, nascido em Pallet, na França, destinado estava à carreira das armas, escolhendo, no entanto, a das letras. Abelardo identificava o real ao particular e considerava o universal como o sentido das palavras (nominum significatio), rejeitando o nominalismo. Dessa forma, o significado dos nomes permitiria esclarecer os conceitos, de forma a emancipar a lógica da metafísica, tornando-a uma disciplina autônoma. O problema dos universais, enfrentado por ele, até hoje serve de exercício de reflexão para os lógicos da contemporaneidade.

Apesar do insólito período de carência de desenvolvimento a que acusam a lógica praticada durante a idade média, Abelardo nos mostra exatamente o oposto: seu estudo continuou vivo, versando sobre temas fundamentais. Os escolásticos ${ }^{19}$ também a ela se dedicaram, denominando-a de rationalis scientia et ars artium: ciência racional e arte das artes. Ciência racional não porque haja ciência que não seja racional, e sim em virtude de que a razão não só dirige os atos de suas partes inferiores, ou seja, daquelas que lhe são naturalmente subordinadas, como também dirige os seus próprios atos.

Em que pese o desenvolvimento experimentado pela lógica até esse momento, os seus postulados continuaram (e ainda continuam) despertando o interesse de notáveis homens das ciências, da filosofia e da matemática através dos tempos. Ultrapassada a idade média, a lógica teria um período de grande prosperidade nas pessoas de ninguém menos que René Descartes, Francis Bacon e outros verdadeiros gênios da humanidade, em que com a crítica feita pelos filósofos da modernidade ao período medievo, identificado por eles como a idade das trevas, é visualizado um:

[...] Grande impulso à lógica material, estabelecendo seus fundamentos pela elaboração pelos métodos indutivo experimental e dedutivo matemático. No século XVIII, Kant considerou a lógica formal como uma ciência final, isto é, uma ciência acabada que já havia atingido um grau de perfeição, não suportando mais nenhuma modificação. No século XIX, Boole e Morgan contestam o filósofo Kant e lançam os fundamentos da logística, isto é, uma nova lógica que emprega símbolos algébricos. Ainda no século XIX, surge Hegel com a lógica dialética que, opondo-se frontalmente à lógica aristotélica, fundamenta-se no princípio da contradição. ${ }^{20}$

Nessa sequência, outro nome surgiria apresentando estudos relevantíssimos sobre a lógica, a ponto de ser colocado ao lado de Aristóteles como um dos maiores lógicos de todos os tempos: Gottlob Frege. Suas idéias foram expandidas principalmente por culpa daqueles que ele influenciou: Russell, Whitehead, Wittgenstein e Carnap. A partir das convicções de Frege, Russel e Whitehead procuraram converter a matemática à lógica, o que ficou conhecido como lógica de segunda vertente ou lógica de segunda ordem. Contudo não é apenas o estudo da lógica clássica que ganha impulso com o passar das eras.

Ao lado da lógica clássica, surgem outros tipos de lógica, que podem ser encaradas como extensões da primeira, apresentando princípios próprios que auxiliam no domínio de áreas específicas do conhecimento. Como exemplo dessas extensões, temos a lógica modal, a

\footnotetext{
${ }^{19}$ A Escolástica foi o método de pensamento crítico dominante no ensino nas universidades medievais europeias de cerca de 1100 a 1500 . Nasceu nas escolas monásticas cristãs, de modo a conciliar a fé cristã com um sistema de pensamento racional, especialmente o da filosofia grega. Colocava uma forte ênfase na dialética para ampliar o conhecimento por inferência e resolver contradições. A obra-prima de Tomás de Aquino, Summa Theologica, é frequentemente vista como exemplo maior dessa corrente de pensamento.
}

${ }^{20}$ DUARTE, Maria Helena Bresser; DUARTE, José Bantim. Noções de filosofia. São Paulo: Ática, 1967. p.14. 
lógica epistêmica, a lógica temporal e, finalmente, a lógica deôntica ${ }^{21}$. Esta última, sendo uma forma de lógica vinculada à moral, agrega os princípios dos direitos, proibições e obrigações. É o sistema de lógica usado para indicar condutas e comportamentos e que inclui as relações de poder entre indivíduos: uma lógica das normas. ${ }^{22}$

\section{LÓGICA JURÍDICA}

A lógica jurídica, tão cara aos operadores do direito e das ciências jurídicas em geral, é classificada como uma subdivisão da lógica deôntica, na qual o objeto principal não são as normas morais, mas sim as normas jurídicas, impostas pelo Estado para proteger os direitos e as expectativas, além de organizar a vida em sociedade. Tal lógica é uma ciência relativamente recente que tem seu ponto de partida definido, sobretudo, com o trabalho de Georg H. Von Wright, An Essay in Modal Logic, e que, desde então, vem conhecendo notável desenvolvimento.

A lógica jurídica serve de instrumental ao jurista, seja no exercício de sua profissão ou no desenvolvimento de sua atividade docente ou de pesquisa científica - momentos que se enredam incessantemente. Não que a lógica jurídica venha a ser uma coletânea de regras para manipular ardilosamente o sistema do direito positivo, adestrando o profissional no caminho do melhor êxito. Interessa-lhe porque o ajuda no seu atuar, realizando o direito e colaborando para o melhor nível científico de sua doutrina. No Brasil, o desenvolvimento da lógica jurídica é confundido com a figura do magistral Lourival Vilanova.

As obras desse renomado jurista ${ }^{23}$ nos remetem não apenas às minúcias e peculiaridades lógicas do sistema de direito positivo, mas também às lições da lógica clássica, ambas de suma importância para adequada formação acadêmica do jurista, dado que este não deve apenas dominar o trato com o sistema de direito positivo, mas também com a ciência do direito construída a partir do estudo de suas normas. Impossível, parece-nos, nos termos colocados por Aristóteles e Vilanova, estudar a lógica distanciada do fenômeno linguístico, ${ }^{24}$ dada a peculiaridade que cada ciência tem de se exprimir mediante determinada linguagem.

"Para que exista lógica jurídica é indispensável que exista linguagem, pois com a linguagem são postas significações. [...]"25. À lógica jurídica, só se chega mediante a

\footnotetext{
${ }^{21} \mathrm{O}$ primeiro tipo agrega à lógica clássica o princípio das possibilidades, enquanto que o segundo soma o princípio da certeza ou da incerteza. A lógica temporal, por sua vez, procura complementar períodos em que o atributo de verdadeiro ou falso não é suficiente, utilizando de um sistema lógico específico que inclui novos operadores para resolver essas situações.

${ }^{22}$ Gottfried Wilhelm Leibniz é o precursor da lógica deôntica. Em 1671, em seus Elementos de direito natural, Leibniz observa a analogia dos conceitos normativos de "justo", "injusto" e "facultativo" com os conceitos aléticos de "necessário", "impossível" e "possível".

${ }^{23}$ As estruturas lógicas e o sistema do direito positivo, causalidade e relação no direito, lógica jurídica e uma série de outros textos esparsos que possuem fundamental importância para o estudo da lógica jurídica.

${ }^{24}$ Se o direito é construído pela linguagem pertencente a determinada cultura, os campos sintático (relação signo - signo), semântico (relação signo-significado) e pragmático (relação signo- intérprete) podem estar presentes em qualquer momento da análise científica.

${ }^{25}$ VILANOVA, Lourival. As estruturas lógicas e o sistema do direito positivo. 3. ed. São Paulo: Noeses, 2005. p. 27.
} 
formalização das linguagens tidas como objeto. O sistema de direito positivo, composto pelas normas jurídicas, é a linguagem-objeto. Sob o prisma lógico, a norma jurídica se apresenta como uma estrutura hipotético-condicional formada por um antecedente (que recorta a realidade social para se constituir) e um consequente (que é o estabelecimento de uma relação jurídica). Tais elementos estão unidos por um vínculo constituído sobre um objeto em comum.

\section{AS ESPÉCIES}

\subsection{ASPECTOS INICIAIS}

O estudo das normas cíveis, a partir da lógica jurídica, mostra que o tipo de estrutura hipotético-condicional formulada pelo juiz no momento da aplicação do direito possui prévia modalidade estrutural, e que atuando em conformidade com tal modalidade, o intérpreteaplicador é capaz de atender aos anseios tidos como necessários no mundo fático, finalizando as lides. Compreendendo a estrutura lógica das normas, entenderemos as peculiaridades das espécies normativas contidas no Código Civil. Lourival Vilanova, seguidor da teoria da estrutura dual da norma jurídica, leciona que a mesma:

[...] Consta de duas partes, que se denominam norma primária e norma secundária.
Naquela, estatuem-se as relações deônticas direitos/deveres, como consequência da
verificação de determinados pressupostos, fixados na proposição descritiva de
situações fáticas ou situações já juridicamente qualificadas; nesta, preceituam-se as
consequências sancionadoras, no pressuposto do não cumprimento do estatuído na
norma determinante da conduta juridicamente devida. ${ }^{26}$

Exemplificando, podemos criar a seguinte proposição normativa com alguns enunciados do Código Civil: Dado o fato de duas pessoas capazes contratarem objeto lícito, possível, determinado ou determinável na forma específica, então deve ser o cumprimento das respectivas obrigações contraídas, bem como os deveres anexos peculiares ao tipo de negócio jurídico. É o entendimento que se constrói a partir dos artigos 113, 422, 427 e outros do Código Civil, a significação extraída a partir dos referidos enunciados prescritivos. Toda e qualquer norma jurídica pode ser reduzida à estrutura acima mencionada.

Distante do modesto exemplo dado, consistente em uma norma primária, a atual seara cível permite que o intérprete não apenas formule uma norma a partir de um comando previamente estabelecido no momento de sua aplicação, mas que também crie o consequente e mesmo parte do antecedente da norma jurídica de acordo com o caso concreto. Não é apenas a subsunção de uma regra específica a um fato que demanda atuação jurisdicional: ${ }^{27}$ é a

\footnotetext{
${ }^{26}$ VILANOVA, Lourival. As estruturas lógicas e o sistema do direito positivo. 3. ed . São Paulo: Noeses, 2005. p. 105.

${ }^{27}$ Conforme posição de Pietro Perlingieri: “[...] ao lado da técnica de legislar com normas regulamentares, ou seja, através de previsões específicas e circunstanciadas, coloca-se a técnica das cláusulas gerais [...]”. PERLINGIERI, Pietro. Perfis do direito civil: introdução ao direto civil constitucional. Tradução de Maria Cristina de Cicco. 2. ed. Rio de Janeiro: Renovar, 2002. p.27.
} 
criação de novas respostas com suporte normativo. O fator que possibilita essa atuação por parte do órgão jurisdicional é a vagueza ${ }^{28}$ contida nos enunciados prescritivos.

Determinadas normas cíveis advindas do Código Civil possuem alto grau de vagueza semântica, atributo que se torna interessante quando estudado à luz da teoria da estrutura dual da norma jurídica. As normas, apesar de tal propriedade, seguem possuindo hipótese e consequente - $\mathrm{D}\left[\left(\mathrm{p} \_\mathrm{q}\right)\right]$ - mas deixam, por vezes, a produção de parte da proposição contida na hipótese (no caso dos conceitos jurídicos indeterminados), ou da proposição contida no consequente (no caso das cláusulas gerais), ${ }^{29}$ a cargo do intérprete-aplicador, que deverá construí-las na análise do caso concreto, de acordo com seu convencimento.

Tomando por referencial o grau e o tipo de vagueza apresentado por cada espécie normativa, podemos diferenciá-las em quatro figuras, classificando-as e expondo suas propriedades assim como as consequências benéficas e deletérias de suas características. São elas: os princípios, as cláusulas gerais, os conceitos jurídicos indeterminados e as regras de conduta. Esta classificação parte da espécie normativa com maior grau de vaguidade (o princípio) até a norma mais precisa e delimitada (a regra), cuja incidência se revela clara e independente de valoração pelo juiz quanto à amplitude de seu âmbito de atuação.

\subsection{As TÉCNICAS LEGISLATIVAS E A INDETERMINAÇÃO DOS ENUNCIADOS}

O estudo das cláusulas gerais, no que se refere à doutrina nacional, ganhou impulso com a promulgação do novo Código Civil, exatamente por tal diploma ter sido confeccionado em grande parte sob o domínio de uma peculiar ferramenta legislativa. ${ }^{30}$ Os caracteres diferenciais dessas espécies normativas - bem como dos conceitos jurídicos indeterminados começam já na construção dos enunciados prescritivos, ${ }^{31}$ nos quais, ainda que textualmente, já são notáveis as diferenças em relação à técnica predominantemente utilizada na elaboração do Código Civil de $1916 .^{3233}$

\footnotetext{
${ }^{28}$ Hodiernamente, é considerado que a ambiguidade, a vaguidade e a carga emotiva traduzem características constantes nos signos que dificultam a tarefa do intérprete do direito, seja na atividade de aplicação das normas ou em seu esforço para descrevê-las. Apesar disso, neste trabalho, ficará claro que a vaguidade (ou vagueza) possui uma importante função se analisarmos a durabilidade de determinado diploma normativo ou a sua capacidade de estar em harmonia com o contexto social que procura regulamentar.

${ }^{29}$ Vale ressaltar a opinião de Gustavo Tepedino: “[...] as cláusulas gerais em codificações anteriores suscitaram compreensível desconfiança, em razão do alto grau de discricionariedade atribuída ao intérprete: ou se tornaram letra morta ou dependiam de uma construção doutrinária capaz de lhes atribuir um conteúdo menos subjetivo". TEPEDINO, Gustavo. Crise de fontes normativas e técnica legislativa na parte geral do Código Civil de 2002. In: TEPEDINO, Gustavo (org.) A parte geral do novo Código Civil: estudos na perspectiva civil-constitucional. Rio de Janeiro: Renovar, 2002. p. 19.

${ }^{30}$ Uma mistura de duas técnicas foi utilizada na elaboração do Código Civil atualmente em vigor.

${ }^{31}$ Os dispositivos, os artigos.

${ }^{32}$ Lei 3.071 de $1^{\circ}$ de Janeiro de 1916.

${ }^{33}$ Dizemos predominantemente pois o Código Civil de 1916 já possuía enunciados elaborados mediante a utilização da técnica legislativa não casuística, como se pode depreender da leitura de seu art. 159, in verbis: Art.
} 
Em termos gerais, podemos diferenciar duas técnicas legislativas comumente utilizadas pelos legisladores na confecção de textos normativos: a técnica casuística e a técnica não casuística (ou generalista). Na técnica casuística, é observada a preferência pela descrição precisa das hipóteses determinantes de uma específica consequência jurídica. $\mathrm{O}$ trabalho legislativo, consequentemente, é mais analítico, delimitando isoladamente cada uma das hipóteses condicionantes de uma característica tese jurídica, ou seja, de um resultado, de uma consequência advinda de uma situação de fato. ${ }^{34}$

Na técnica não casuística (generalista), por sua vez, ao invés de delimitar in casu cada hipótese geradora de determinada consequência jurídica, o legislador opta por generalizar o conteúdo do enunciado, criando apenas uma hipótese que incide sobre uma vasta gama de fatos abrangidos pela sua descrição. O processo lógico utilizado nessa atividade é o da indução, ou seja, a determinação de enunciados gerais aplicáveis a uma dada classe de fatos a partir de situações particulares. É da utilização desta técnica que resulta a maioria das espécies normativas abordadas neste trabalho. ${ }^{35}$

\subsection{PRINCÍPIOS}

Já foi dito que os princípios ${ }^{36}$ representam, junto ao sistema de direito positivo, os valores que inspiram as produções normativas. $\mathrm{O}$ vocábulo princípio traz à mente a ideia de início, de fundamento de algo. E, em verdade, esses tipos normativos são os fundamentos do ordenamento jurídico, dada a importância das funções que desempenham. Espécie normativa multifacetária, os princípios jurídicos recebem um tratamento peculiar da ciência do direito, o que consiste em diferentes abordagens a partir de critérios diversos. Dentre elas, desponta a abordagem de Canaris, indicando que:

$\mathrm{Na}$ verdade, a passagem do valor para o princípio é extraordinariamente fluída; poder-se-ia dizer, quando se quisesse introduzir uma diferenciação de algum modo praticável, que o princípio está já num grau de concretização maior que o do valor:

159. Aquele que, por ação ou omissão voluntária, negligência, ou imprudência, violar direito, ou causar prejuízo a outrem, fica obrigado a reparar o dano.

${ }^{34}$ Como exemplo, podemos citar o parágrafo único do art. $5^{\circ}$ do Código Civil de 2002: Art. 5을 A menoridade cessa aos dezoito anos completos, quando a pessoa fica habilitada à prática de todos os atos da vida civil. Parágrafo único. Cessará, para os menores, a incapacidade: I - pela concessão dos pais, ou de um deles na falta do outro, mediante instrumento público, independentemente de homologação judicial, ou por sentença do juiz, ouvido o tutor, se o menor tiver dezesseis anos completos; II - pelo casamento; III - pelo exercício de emprego público efetivo; IV - pela colação de grau em curso de ensino superior; V - pelo estabelecimento civil ou comercial, ou pela existência de relação de emprego, desde que, em função deles, o menor com dezesseis anos completos tenha economia própria.

\footnotetext{
${ }^{35}$ Para exemplificar o resultado da utilização desta técnica legislativa, temos, dentre outros, o art. 422 do CC, onde a indeterminação aparece como a primeira característica observável no enunciado: Art. 422. Os contratantes são obrigados a guardar, assim na conclusão do contrato, como em sua execução, os princípios de probidade e boa-fé.

${ }^{36}$ Como exemplos de princípios da seara cível temos: o princípio da personalidade, o princípio da autonomia da vontade, o princípio da liberdade de estipulação negocial, o princípio da propriedade individual, o princípio da intangibilidade familiar e muitos outros de importância inquestionável.
}

Revista de Direito Brasileira | São Paulo, SP | v. 13 | n. 6 | p. 111 - 130 | jan./abr. 2016 
ao contrário deste, ele já compreende a bipartição, característica da proposição de Direito em previsão e consequência jurídica. [... $]^{37}$

Essas espécies normativas apresentam grande dificuldade de análise por assumirem uma variada gama de funções. Os princípios jurídicos são marcadamente multifuncionais, pela sua abertura semântica e essência axiológica. Algumas de suas funções são a supletiva e a interpretativa, ambas associadas aos caracteres fundamentais para a manutenção do sistema de direito positivo. Não deve ser negligenciada, contudo, a assertiva de que, em primeiro lugar, os princípios têm, ao lado das regras, função normativa. E sendo normas jurídicas, podem ser concretizados gerando direitos subjetivos.

Ademais, os princípios jurídicos apresentam uma estreita relação com as outras espécies normativas. Seja dirigindo sua interpretação (no caso de uma regra), ou atuando juntamente com elas no momento da aplicação do direito (como no caso de uma cláusula geral, em que pode haver uma assimilação recíproca das espécies), os princípios possuem função basilar em todo sistema de direito positivo. Nesse sentido, leciona Judith Martins Costa, ao dissertar sobre a dinâmica do princípio com a cláusula geral, a partir da estrutura apresentada por esta última:

[...] Por vezes --- e aí encontraremos as cláusulas gerais propriamente ditas --- o seu enunciado, ao invés de traçar pontualmente a hipótese e as suas consequências, é desenhado como uma vaga moldura, permitindo, pela vagueza semântica que caracteriza os seus termos, a incorporação de princípios, diretrizes e máximas de conduta originalmente estrangeiros ao corpus codificado, do que resulta, mediante a atividade de concreção destes princípios, diretrizes e máximas de conduta, a constante formulação de novas normas. ${ }^{38}$

\subsection{CLÁUSULAS GERAIS E CONCEITOS JURÍDICOS INDETERMINADOS}

As cláusulas gerais ${ }^{39}$ e os conceitos jurídicos indeterminados ${ }^{40}$ são efeitos diretos da utilização da técnica legislativa não casuística. O grau de indeterminação de seus enunciados é propositalmente almejado pelo legislador, que procura, além de uma maior incidência dos efeitos de seu texto normativo, a durabilidade de sua obra, uma vez que, não raro, os diplomas legislativos construídos sob o império da técnica casuística sofrem um processo de "envelhecimento" precoce em seu conteúdo, dado o descompasso existente entre a rigidez de suas prescrições e a mutabilidade da dinâmica da sociedade.

\footnotetext{
${ }^{37}$ CANARIS, Claus-Wilhelm. Pensamento sistemático e conceito de sistema na ciência do direito. Tradução de Antônio Menezes Cordeiro. Lisboa: Calouste Gulbenkian, 1989. p. 86.

${ }^{38}$ COSTA, Judith Hofmeister Martins. O Direito Privado como um "sistema em construção": as cláusulas gerais no projeto do Código Civil brasileiro. Jus Navigandi, Teresina, ano 5, n. 41, maio, 2000 . Disponível em: <http://jus.com.br/artigos/513>. Acesso em: 8 out. 2013.

${ }^{39}$ São exemplos de cláusulas gerais no Código Civil, sem prejuízo de outras identificadas pela doutrina, a cláusula geral da boa-fé (art. 422), a cláusula geral da responsabilidade civil (art. 186 c/c 927), a cláusula geral da função social do contrato (art. 421) e a cláusula geral do melhor interesse da criança e do adolescente.

${ }^{40} \mathrm{Um}$ bom exemplo de conceito jurídico indeterminado é o do parágrafo único do art. 927 do CC de 2002, que trata da "atividade de risco". Vejamos que, no exemplo, a dúvida está no significado (conteúdo/pressuposto) de "atividade de risco" e não nas consequências jurídicas resultantes (responsabilidade civil objetiva).
} 
Fica claro, dentre o exposto até o presente momento, que o grau de indeterminação é o fator que diferencia os tipos normativos agora analisados dos outros tipos normativos ${ }^{41}$ presentes na codificação civil. Mas como poderíamos dar um tratamento jurídico específico para tais tipos? Na verdade, tomando o sistema de direito positivo como um corpus constituído de linguagem, concluiremos como já dito anteriormente que suas unidades básicas são as normas jurídicas, formuladas, por sua vez, a partir de um processo intelectivo que começa com a leitura dos enunciados prescritivos contidos nas leis. ${ }^{42}$

A indeterminação atribuída aos enunciados prescritivos advém de uma característica atribuída aos signos (símbolos, palavras) que compõem os textos normativos sobre os quais se assenta o sistema do direito positivo. ${ }^{43}$ Essa característica é a vaguidade, como já salientamos brevemente em outro tópico. A vaguidade (ou vagueza) pode ser definida como a imprecisão de significado existente em determinado símbolo. É um estado de incerteza, de penumbra, no que se refere ao sentido de determinada disposição presente no texto. Por ser tão comum ao cotidiano do jurista, acaba sendo dividida em vagueza comum e vagueza socialmente típica.

Ancorado na utilização das normas vagas, o direito civil contemporâneo permite o constante arejamento do sistema jurídico, comunicando os diversos diplomas (Constituição Federal, Código Civil e Microssistemas) e recepcionando os anseios e conceitos que emanam da própria sociedade. Figuram nesse contexto, com importância ímpar, a cláusula geral e o conceito jurídico indeterminado, espécies normativas a que nos colocamos a examinar. Rodrigo Reis Mazzei, em eminente lição, propicia um importante ensinamento sobre essas duas figuras:

[...] Havendo identidade quanto a vagueza legislativa intencional, determinando que o judiciário faça a devida integração sobre a moldura fixada, a cláusula geral demandará do julgador mais esforço intelectivo. Isso, porque, em tal espécie legislativa, o magistrado, (1) além de preencher o vácuo que corresponde a um conceito jurídico indeterminado (e/ou princípios), (2) é compelido a fixar a consequência jurídica correlata e respectiva ao preenchimento anterior. No conceito jurídico indeterminado, o labor é mais reduzido, pois, como simples enunciação abstrata, o julgador, após efetuar a preenchimento valorativo, já estará a julgar de acordo com a consequência previamente estipulada em texto legal.[... $]^{44}$

Em posição ainda mais específica, Marcelo da Rocha Rosado complementa:

No âmbito das normas que possuem, em seu bojo, categorias de alto grau de vagueza semântica, e que enviam o aplicador à análise de instâncias valorativas metajurídicas ou referentes a realidades fáticas mutáveis, é possível distinguir dois fenômenos. Enfocando o conteúdo lógico da norma, temos que sua estrutura consiste em um antecedente (no qual se faz a descrição hipotética do fato sobre o qual deve a norma incidir) e um consequente (no qual se estipula a consequência jurídica advinda da concretização do fato e sua subsunção à norma). Assim, a imprecisão legal pode recair tanto no antecedente da norma, quanto no seu consequente. São duas realidades ou métodos para se conferir flexibilidade ás normas, cujo reconhecimento merece acurada abordagem pelo estudioso do direito. Nessa ótica, a diferença entre conceitos jurídicos indeterminados e cláusulas gerais consiste na posição de cada um na estrutura da norma. Os conceitos jurídicos

\footnotetext{
${ }^{41}$ Tal como os princípios e as regras de conduta.

${ }^{42}$ Este tema já foi tratado na introdução.

${ }^{43} \mathrm{Na}$ análise em questão, a vaguidade é intencionalmente utilizada para ceder uma maior mobilidade interpretativo-discursiva ao intérprete-aplicador, apesar de seu trabalho ser dificultado em alguns pontos.
}

${ }^{44}$ MAZZEI, Rodrigo. Código Civil de 2002 e o judiciário: apontamentos na aplicação das cláusulas gerais. In: DIDDIER JR, Fredie; MAZZEI, Rodrigo (coord). Reflexos do novo código civil no direito processual. Salvador: Juspodvm, 2006. p.34-35. 
indeterminados alocam-se no antecedente da norma, descrevendo hipóteses abertas para a incidência da norma. As cláusulas gerais, por sua vez, residem no consequente da norma, pois a solução a ser dada para o caso concreto que se ajusta ao antecedente da norma não é rigidamente conferida pelo sistema, devendo ser moldada pelo magistrado, conforme as exigências do caso concreto. [.... $]^{45}$

Independentemente do tipo de vagueza configurada, o efeito dessa característica será o mesmo: o conteúdo da norma geral e abstrata a ser utilizada pelo juiz na resolução do caso concreto será incompleto, o que demandará um esforço hermenêutico de grande monta para a complementação da hipótese e da consequência normativa que deverão incidir sobre o(s) fato(s) levado(s) ao judiciário, no contexto de um conflito de interesses entre partes que buscam a tutela jurisdicional. Aqui o juiz, ao que parece, acaba por receber uma parte dos poderes atribuídos ao legislador. ${ }^{46}$

Dizemos isso na medida em que percebemos que as normas gerais e abstratas formuladas a partir dos enunciados do Código Civil (e de outros textos avulsos) só formarão hipóteses de incidência após uma prévia valoração do próprio juiz, que, agora, ao invés de buscar os modelos de conduta determinantes de consequências jurídicas no Código, será o responsável, mesmo, pela determinação de quais modelos são passíveis de proteção jurídica ou não, podendo, ainda, delimitar as consequências jurídicas das condutas por ele examinadas.

Esta afirmação encontra respaldo no próprio tipo de vagueza que configura as cláusulas gerais e os conceitos jurídicos indeterminados. Diferentemente da vagueza comum, esses tipos normativos padecem da vagueza socialmente típica ${ }^{47}$, que remete a busca do sentido dos termos normativos para a linguagem da realidade social, ou seja, para o ambiente litigioso que deve ser ordenado pelo direito. O significado dos termos, bem como a licitude de uma conduta, assim, só poderão ser completamente entendidos a partir do exame semântico dos usos, práticas e condutas contextualizados no meio social. ${ }^{48}$

\footnotetext{
${ }^{45}$ ROSADO, Marcelo da rocha. Alguns aspectos relevantes da usucapião e da expropriação privada. In: MAZZEI, Rodrigo (Coord). Questões processuais no novo Código Civil. Barueri: Manole, 2006. p.416-417.

${ }^{46}$ Que segundo o modelo tripartido de divisão dos poderes, é o responsável por ditar as normas gerais e abstratas a serem seguidas pelos jurisdicionados. Caberia ao juiz, segundo tal teoria, apenas a pronuncia das próprias determinações do legislador aos casos levados ao crivo do judiciário, emitindo, assim, normas individuais e concretas.
}

${ }^{47}$ JORGE JR, Alberto Gosson. Cláusulas Gerais e o novo Código Civil. São Paulo: Saraiva, 2004. p. 06.

${ }^{48}$ RECURSO ESPECIAL. DIREITO CAMBIÁRIO. AÇÃO DECLARATÓRIA DE NULIDADE DE TÍTULO DE CRÉDITO. NOTA PROMISSÓRIA. ASSINATURA ESCANEADA. DESCABIMENTO. INVOCAÇÃO DO VÍCIO POR QUEM O DEU CAUSA. OFENSA AO PRINCÍPIO DA BOA-FÉ OBJETIVA. APLICAÇÃO DA TEORIA DOS ATOS PRÓPRIOS SINTETIZADA NOS BROCARDOS LATINOS 'TU QUOQUE' E 'VENIRE CONTRA FACTUM PROPRIUM'. 1. A assinatura de próprio punho do emitente é requisito de existência e validade de nota promissória. 2. Possibilidade de criação, mediante lei, de outras formas de assinatura, conforme ressalva do Brasil à Lei Uniforme de Genebra. 3. Inexistência de lei dispondo sobre a validade da assinatura escaneada no Direito brasileiro. 4. Caso concreto, porém, em que a assinatura irregular escaneada foi aposta pelo próprio emitente. 5. Vício que não pode ser invocado por quem the deu causa. 6 . Aplicação da 'teoria dos atos próprios', como concreção do princípio da boa-fé objetiva, sintetizada nos brocardos latinos 'tu quoque' e 'venire contra factum proprium', segundo a qual ninguém é lícito fazer valer um direito em contradição com a sua conduta anterior ou posterior interpretada objetivamente, segundo a lei, os bons costumes e a boa-fé 7. Doutrina e jurisprudência acerca do tema. 8. RECURSO ESPECIAL DESPROVIDO. (REsp 1192678/PR, Rel. Ministro PAULO DE TARSO SANSEVERINO, TERCEIRA TURMA, julgado em 13/11/2012, DJe 26/11/2012).

Revista de Direito Brasileira | São Paulo, SP | v. 13 | n. 6 | p. 111 - 130 | jan./abr. 2016 
Dito de outra forma, na vagueza socialmente típica o legislador procura programar o reenvio de valores para dentro do ordenamento jurídico (através da atividade jurisdicional), uma vez que o enunciado prescritivo por si só não determina critérios adequados para a delimitação de seu significado, havendo a necessidade de se recorrer a parâmetros variáveis da moral de dos bons costumes encontrados no ambiente social. ${ }^{49} \mathrm{Na}$ hipótese de aplicação de uma cláusula geral, essa atividade será mais exaustiva, ao passo que, no caso de aplicação de um conceito jurídico indeterminado, o esforço hermenêutico será mais superficial.

Devemos ressaltar que, sem essa atividade, a norma jurídica jamais será capaz de adquirir sentido deôntico completo. A deficiência nas significações necessárias para a formação da norma jurídica acarretará a incompletude da mesma. Sem a totalidade de seu conteúdo, a norma não será capaz de determinar uma prescrição, seja uma permissão, uma obrigação ou uma proibição, na forma dos modais deônticos possíveis de serem encontrados nas normas jurídicas. Em resumo, tornar-se-ia inoperante. Por consequência, somos levados a reafirmar a nova posição ocupada pelo juiz frente à promulgação do novo Código Civil.

É de se esperar que o sistema de direito positivo, enquanto ordem necessária para a regulamentação das condutas humanas imprescindíveis para a convivência social, seja um sistema promotor de valores, tal como a segurança jurídica, a previsibilidade e a paz. Para tanto, necessário é um sistema cujas respostas aos casos concretos estejam já minimamente estabelecidas, sejam consubstanciadas em normas ou como produto da interpretação autêntica da autoridade competente, que, todavia, não poderá ultrapassar os limites impostos por aquele mesmo sistema.

As características contidas nas cláusulas gerais, nos conceitos jurídicos indeterminados e nos princípios colocam em dúvida essa previsibilidade, dado que a amplitude interpretativa dos mesmos confere maior liberdade ao juiz, gerando a possibilidade da criação de novas "respostas". A averiguação de que tais "respostas" devem seguir parâmetros condizentes com o próprio sistema de direito positivo é o que justificou este trabalho, ${ }^{50}$ sob o risco do sacrifício dos valores acima descritos, tão necessários à manutenção da sociedade.

\footnotetext{
${ }^{49}$ DIREITO CIVIL. AGRAVO REGIMENTAL NO AGRAVO DE INSTRUMENTO. SEGURO DE VIDA. SUICÍDIO. ART. 798 DO CC/2002. PREMEDITAÇÃO. COMPROVAÇÃO PELA SEGURADORA. PRESUNÇÃO DE BOA-FÉ DO SEGURADO. REVISÃO. SÚMULA N. 7/STJ. DECISÃO MANTIDA. 1. A ocorrência do suicídio antes do prazo bienal previsto no art. 798, caput, do CC/2002 não exime, por si só, a seguradora, do dever de indenizar. Referido dispositivo legal deve ser interpretado em consonância com os princípios da lealdade e da boa-fé objetiva que norteiam o novo Código Civil (arts. 113 e 422 do CC/2002). 2. A obrigação da seguradora de pagar a indenização securitária somente pode ser afastada se ela comprovar a ocorrência de má-fé ou premeditação do segurado, a teor das Súmulas n. 105/STF e 61/STJ. 3. Alterar a conclusão do Tribunal de origem, que com base nos elementos de prova dos autos, entendeu pela não premeditação do suicídio, é inviável na via especial, haja vista o óbice da Súmula n. 7/STJ. 4. Agravo regimental a que se nega provimento. (AgRg no Ag 1166827/RS, Rel. Ministro ANTONIO CARLOS FERREIRA, QUARTA TURMA, julgado em 06/11/2012, DJe 13/11/2012).
}

\footnotetext{
${ }^{50} \mathrm{Em}$ uma busca praticamente diária pela jurisprudência, descobrimos a total inexistência de parâmetros interpretativos sólidos para a utilização das cláusulas gerais. Não existe um julgado que delimite a amplitude ou faça restrições à aplicação desse tipo normativo. Recorremos, então, à doutrina, onde a falta de uma teoria da decisão acabou por incentivar a busca de uma solução dogmática totalmente aplicável à atividade de nossos tribunais e que poderia abrir algum novo horizonte sobre a maneira de se encarar as inovações legislativas de nosso século.
}

Revista de Direito Brasileira | São Paulo, SP | v. 13 | n. 6 | p. 111 - 130 | jan./abr. 2016 


\subsection{REGRAS DE CONDUTA}

Pouco há para ser dito, para o deslinde deste trabalho, sobre esta espécie normativa. A regra de conduta ${ }^{51}$ é uma norma jurídica que possui seu comando inteiramente estabelecido, não suscitando valorações ou um trabalho hermenêutico mais denso por parte do intérprete. Presentes os pressupostos de fato, a norma desta espécie incidirá sem maiores delongas. $\mathrm{O}$ conteúdo de tal norma já está predisposto no texto normativo, não existindo necessidade de se recorrer a qualquer outro meio para a delimitação de sua hipótese de incidência ou de seu consequente. Ele é resultado da utilização da técnica casuística de legislar.

\section{O PRECEDENTE JUDICIAL COMO UMA POSSÍVEL SOLUÇÃO}

Como poderíamos alinhar a abertura hermenêutica com a previsibilidade e a segurança que é indispensável para o correto desenrolar das relações sociais? O advento dessas espécies normativas, agora utilizadas em grande escala, chegou a produzir manifestações doutrinárias que preconizam a morte da concepção de sistema de direito positivo, e, consequentemente, de seus valores. ${ }^{52}$ Pensamos, contudo, que essa postura é exagerada, havendo a total possibilidade de harmonização da abertura hermenêutica consagrada na nova legislação civil com a segurança e a previsibilidade do texto anterior.

O instituto que permitiria tal harmonização é resultado de estudos recentes pela doutrina pátria, que observando os países pertencentes à grande família jurídica da Common Law, tem procurado apontar os pontos de interseção entre esta e a família a qual pertencemos: a Civil Law. É o precedente judicial, que pode ser definido como "a decisão judicial tomada à luz de um caso concreto, cujo núcleo essencial pode servir como diretriz para o julgamento posterior de casos análogos". ${ }^{53}$ Instituto esse existente, com maior ou menor força, em todos os ordenamentos jurídicos do mundo.

Contemporaneamente, com a tenra perda de credibilidade e confiança da sociedade na justiça e nos juízes, decorrente da elevação da consciência jurídica da população e de seu grau de exigência em relação ao desempenho do judiciário, os países que adotam a Civil Law têm se voltado para alguns parâmetros da Common Law e vice-versa. ${ }^{54}$ Trata-se de uma forma de controlar a atividade do judiciário, de compreender quais são as bases utilizadas para as decisões e se tais decisões respondem aos anseios da lei criada pela sociedade para sua própria regulamentação.

\footnotetext{
${ }^{51} \mathrm{O}$ art. 1.784 do Código Civil é um preciso exemplo de regra de conduta.

${ }^{52}$ Nesse sentido está o artigo A morte e a morte da concepção sistemática do Direito Privado: abertura hermenêutica, tópica e cláusulas gerais, escrito pelo professor Veceslau Tavares Costa Filho. Revista de Informação Legislativa ,v. 48, n. 189, jan./marc. 2011. p. 147-156.

${ }^{53}$ DIDIER JR. Fredie; BRAGA, Paula Sarno; OLIVEIRA, Rafael. Curso de direito processual civil. V.2. 4. ed. São Paulo: Juspodivm, 2009. p. 381.

${ }^{54}$ GRECO, Leonardo. Instituiçães de processo civil. V. 1. Rio de Janeiro: Forense, 2010. p. 3.
} 
O contexto fático deste trabalho é, dessa forma, marcado pela confluência de valores significativamente opostos: a liberdade interpretativa dada ao juiz ${ }^{55}$ é contestada frente a exigência de respostas feita ao judiciário. Da mesma forma, a cautela decisória, inerente à segurança jurídica, é confrontada com a demanda pela efetividade das decisões judiciais e o prazo razoável para a realização do processo. Nada mais indicativo da consolidação do Estado democrático de direito, no qual a pauta de valores escolhida pelo legislador não retira do cenário jurídico a opção valorativa feita pela sociedade.

Pois bem. Há muito é dito que a jurisdição é uma atividade criadora da norma jurídica para o caso concreto, tal como é criada, muitas vezes, a própria regra abstrata. Devemos deixar de lado a opinião de que o Poder Judiciário só exerce a função de legislador negativo, para compreender que ele, de fato, concretiza o ordenamento jurídico diante do caso concreto. ${ }^{56}$ Assim, é construída, por meio de uma atividade criativa, a decisão judicial de acordo com o diligente convencimento, sendo procurado, no legislativo, os fundamentos para a mesma (legislação, princípios e outros mais) e o amparo necessário a sua motivação.

Como cediço, toda decisão judicial deve ser fundamentada sob pena de nulidade ${ }^{57}$ (art. 93, IX da CFRB/88). Decisões que se reportam exclusivamente a artigos de lei ou empreguem conceitos jurídicos indeterminados sem explicitar sua incidência no caso concreto, invocando razões genéricas, comuns a toda decisão, não podem ser entendidas como fundamentadas. É, em verdade, uma decisão tautológica, ou seja, a conclusão confirma a premissa já afirmada ao invés de justificá-la. No caso dos tipos normativos aqui estudados, essa exigência deve ser levada ao extremo, pelos motivos já apontados.

Sendo o precedente a decisão judicial tomada à luz de um caso concreto cujo núcleo essencial pode servir como diretriz para o julgamento posterior de casos análogos, devemos inferir que este é composto de dois elementos: “[...] a) as circunstâncias de fato que embasam a controvérsia; e b) a tese ou o princípio jurídico assentado na motivação (ratio decidendi) do provimento decisório". 58

Para constituir um precedente, a decisão tem que enfrentar todos os principais argumentos relacionados à questão de direito do caso concreto, além do mesmo poder necessitar de inúmeras outras decisões para ser definitivamente delineado. O precedente é a primeira decisão que elabora a tese jurídica ou é a decisão que definitivamente a delimita, deixando-a cristalina. $\mathrm{O}$ fundamento do precedente está em produzir uma norma jurídica com potencial de aplicação a uma infinidade de casos análogos futuros, visando a assegurar uma maior previsibilidade na realização do direito, ao tratar da mesma forma casos iguais.

\footnotetext{
${ }^{55} \mathrm{Na}$ visão de Alberto Gosson Jorge Jr., é inegável o papel assumido pela jurisprudência nas decisões que aplicam cláusulas gerais. Dada a indeterminação congênita de que são portadores seus dispositivos, a concretização da norma será feita pelas sentenças e decisões, que a cada caso específico colhido nos conflitos sociais irão conferir a interpretação adequada aos valores e aos princípios pertinentes à cláusula geral. JORGE JR, Alberto Gosson. Cláusulas gerais e o novo Código Civil. São Paulo: Saraiva, 2004. passim.

${ }^{56}$ ÁVILA, Humberto. Teoria dos princípios - da definição à aplicação dos princípios jurídicos. 7. ed. São Paulo: Malheiros, 2007. p. 34.

${ }^{57}$ RODRIGUES, Marcelo Abelha. Manual de direito processual civil. 5. ed. rev. atual. e ampl. São Paulo: Revista dos Tribunais, 2010. p. 73-74.

${ }^{58}$ TUCCI, José Rogério Cruz e. Precedente judicial como fonte do direito. São Paulo: Revista dos Tribunais, 2004. p. 12.
} 
Havendo similares circunstâncias de fato, acreditamos que o juiz deva se vincular à sua própria decisão, resolvendo da mesma forma os casos semelhantes que, porventura, sejam levados ao crivo do judiciário. Deste feito, não se mina a liberdade interpretativa, balanceando-a com a previsibilidade necessária referente às decisões posteriores vindas daquele mesmo juízo. O mesmo raciocínio deve ser aplicado às decisões das cortes superiores: elas também estão obrigadas a observá-las. Em último caso, a responsabilidade por toda liberdade interpretativa será colocada sobre os Tribunais.

Portanto, acreditamos que a combinação das técnicas decisórias relativas aos precedentes judiciais, no que se refere à técnica relativa ao gênero dos conceitos vagos, é apontada como o parâmetro mais eficaz de manutenção da segurança jurídica sem mitigar o espírito da nova legislação. É uma excelente oportunidade, ainda, para o estudo da instrumentalidade do direito processual em relação ao direito material, uma vez que a escolha de um instituto pelo legislador acabou por antecipar o desenvolvimento de outro em uma seara totalmente diversa.

\section{CONSIDERAÇÕES FINAIS}

A chegada do século XXI expandiu os horizontes investigativos do jurista brasileiro. Este, agora, se vê desafiado ao se deparar com a diversidade de espécies normativas presentes na codificação de 2002. Construído mediante uma peculiar técnica legislativa mista, o atual Código Civil permite a revitalização do sistema jurídico, comunicando diversos diplomas (Constituição e Microssistemas) e recepcionando os anseios que emanam da sociedade. Ao mesmo tempo, o novo diploma demanda daqueles que o utilizam o conhecimento de algumas questões prévias de importância considerável.

Em nossa época, essa tendência deve ser reforçada, uma vez que o próprio objeto apresenta algumas dificuldades de operacionalização que demandam uma considerável reflexão por parte daqueles que investigam as normas, e uma reflexão ainda maior por parte daqueles que as aplicam. É irrefutável que o magistrado foi investido de novos poderes com a codificação de 2002. Sua mobilidade interna ao discurso jurídico foi ampliada e com ela a discricionariedade acerca da melhor solução para a lide levada a juízo, na qual deve constar uma correspondência entre os seus atos e o tipo de Estado sob o qual nos encontramos.

Denunciamos durante este trabalho que a estrutura da norma jurídica, quando analisada sob o prisma da lógica jurídica, é composta de uma hipótese (descritora de um fato de possível ocorrência no mundo fático) e de uma tese (ou consequência, que é o resultado jurídico de tal ocorrência). No Código Civil, por vezes, ao invés de termos normas jurídicas com sua estrutura totalmente completa, temos as cláusulas gerais, os princípios e os conceitos jurídicos indeterminados que dependem da valoração judicial, gerando discricionariedade ao intérprete-aplicador. Preocupava-nos encontrar limitações para tal discricionariedade.

As respostas foram encontradas: resta dizer que, em todos os casos, a vagueza identificada nesses tipos normativos tem a possibilidade de ser preenchida de acordo com parâmetros que revelam a manutenção da concepção sistemática do direito. No campo interpretativo, temos a manutenção da referida concepção através da utilização de ferramentas hermenêuticas, tal como uma concepção totalizante do momento interpretativo ou o respeito à natureza do instituto em questão. No meio processual, encontramos também um importante recurso de uniformização das decisões, através do instituto jurídico do precedente judicial. 


\section{REFERÊNCIAS}

ARISTÓTELES. Órganon: categorias, da interpretação, analíticos anteriores, analíticos posteriores, tópicos, refutações sofísticas. Tradução, textos adicionais e notas de Edson Bini. 2. ed. São Paulo: Edipro, 2010.

ÁVILA, Humberto. Teoria dos princípios - da definição à aplicação dos princípios jurídicos. 7. ed. São Paulo: Malheiros, 2007.

CANARIS, Claus-Wilhelm. Pensamento sistemático e conceito de sistema na ciência do direito. Tradução de Antônio Menezes Cordeiro. Lisboa: Calouste Gulbenkian, 1989.

CARVALHO, Paulo de Barros. Direito tributário: fundamentos jurídicos da incidência. São Paulo: Saraiva, 1998.

CHAUÍ, Marilena. Introdução à história da filosofia: dos pré-socráticos a Aristóteles. V.1. 2. ed. São Paulo: Companhia das Letras, 2002.

COSTA, Judith Hofmeister Martins. O Direito Privado como um "sistema em construção": as cláusulas gerais no projeto do Código Civil brasileiro. Jus Navigandi, Teresina, ano 5, n. 41, maio, 2000 . Disponível em: <http://jus.com.br/artigos/513>. Acesso em: 8 out. 2013.

DIDIER JR. Fredie; BRAGA, Paula Sarno; OLIVEIRA, Rafael. Curso de direito processual civil. V.2. 4. ed. São Paulo: Juspodivm, 2009.

DUARTE, Maria Helena Bresser; DUARTE, José Bantim. Noções de filosofia. São Paulo: Ática, 1967.

GRECO, Leonardo. Instituições de processo civil. V.1. Rio de Janeiro: Forense, 2010.

JORGE JR, Alberto Gosson. Cláusulas gerais e o novo Código Civil. São Paulo: Saraiva, 2004.

KELSEN, Hans. Teoria geral das normas. Tradução de José Florentino Duarte. Porto Alegre: Fabris, 1986.

MAZZEI, Rodrigo. Código Civil de 2002 e o judiciário: apontamentos na aplicação das cláusulas gerais. In: DIDDIER JR, Fredie; MAZZEI, Rodrigo (coord). Reflexos do novo código civil no direito processual. Salvador: Juspodvm, 2006.

MOUSSALLEM, Tárek Moysés. Fontes do direito tributário. São Paulo: Noeses, 2006.

PERLINGIERI, Pietro. Perfis do direito Civil: introdução ao direto civil constitucional. Tradução de Maria Cristina de Cicco. 2. ed. Rio de Janeiro: Renovar, 2002.

RODRIGUES, Marcelo Abelha. Manual de direito processual civil. 5. ed. rev. atual. e ampl. São Paulo: Revista dos Tribunais, 2010.

ROSADO, Marcelo da rocha. Alguns aspectos relevantes da usucapião e da expropriação privada. In: MAZZEI, Rodrigo (Coord). Questões processuais no novo Código Civil. Barueri: Manole, 2006.

SANTOS, Mário Ferreira dos. Lógica e dialética: lógica, dialética, decadialética. 4. ed. São Paulo: Logos, 1959. 
SGARBI, Adrian. Clássicos da teoria do direito. Rio de Janeiro: Lumen Juris, 2006.

SILVA, Ivan de Oliveira. Curso de lógica geral e jurídica. São Paulo: Atlas, 2009.

TEPEDINO, Gustavo. Crise de fontes normativas e técnica legislativa na parte geral do Código Civil de 2002. In: TEPEDINO, Gustavo (org.) A parte geral do novo Código Civil: estudos na perspectiva civil-constitucional. Rio de Janeiro: Renovar, 2002.

TUCCI, José Rogério Cruz e. Precedente judicial como fonte do direito. São Paulo: Revista dos Tribunais, 2004.

VILANOVA, Lourival. As estruturas lógicas e o sistema do direito positivo. 3. ed. São Paulo: Noeses, 2005. 